\title{
UMA ANALÍTICA DA BELEZA CORPORAL: NOTAS A PARTIR DE KANT
}

Rafael da Silva Mattos

\section{Resumo}

Ao escrever sua obra "Crítica da Faculdade do Juízo", Kant faz uma analítica do belo e do sublime. Esse artigo tem por objetivo discutir a beleza corporal na atualidade à luz do referencial teórico e conceitual kantiano. Trata-se de compreender se as expressões "belo" e "sublime" se aplicam a beleza corporal, tema presente no cotidiano dos profissionais de Educação Física, em especial nas academias de ginástica e musculação. A Educação Física como prática social produtora de conhecimento e de saberes torna-se parceira da Filosofia, disciplina criadora de conceitos, para pensar e refletir sobre o corpo na atualidade.

\section{Palavras-Chave}

Belo; Sublime; Kant; Educação Física.

\section{AN ANALYTICAL OF BODY BEAUTY: NOTES FROM KANT}

\section{Rafael da Silva Mattos}

\begin{abstract}
In his book "Critique of the Power of Judgment", Kant makes an analysis of the beauty and the sublime. This article aims to discuss the body beauty in the light of current Kant's theoretical framework and conceptual. It is understood that the terms "beauty" and "sublime" applies for the body beauty, this issue represents the daily Physical Education professionals, especially in fitness centers and gyms. The Physical Education as a social practice producer of knowledge and learning becomes a partner of Philosophy, creative discipline of concepts, to think and contemplate on the body at the present.
\end{abstract}

\section{Key-Words}

Beauty; Sublime; Kant; Physical Education. 


\section{INTRODUÇÃO}

Todos, em algum momento, já escutamos frases do tipo: "João é bonito" ou "João é belo". Na experiência dos profissionais de Educação Física, em especial nas academias de ginástica e musculação, é muito comum encontrar a preocupação com o corpo belo. Todos querem, em algum grau, ser belos. Não é raro uma mulher, praticante de musculação, dizer que se sente mais bela depois que começou a “malhar". Questionando os homens, a unanimidade prevalece: "Ela é uma mulher muito bonita, bela, gostosa". Se nos debruçarmos sobre os textos de Sabino (2005, 2007a, 2007b), veremos que a busca bioascética pela beleza é comum entre homens e mulheres nas academias. As mulheres buscam desenvolver e definir os glúteos e fugir do padrão tradicional de mulher com aspecto frágil e delicado. No reino do fitness, querem ser desejadas e admiradas pela sua beleza corporal.

No entanto, quando utilizamos uma abordagem filosófica para tratar de um objeto de estudo, devemos atentar para o rigor conceitual. Considerando a Filosofia como a criação de conceitos, na linguagem de Deleuze e Guattari (1991), não há nada mais equivocado e fútil do que cometer deslizes conceituais. Desrespeitar o conceito é desprezar a Filosofia como campo de conhecimentos e saberes. Maigné (2005), leitor de Deleuze, ratifica que a filosofia não demonstra nem prova nada, tampouco se inspira na verdade. A filosofia, nessa concepção, não pretende ter aderência ao real e recusa aproximações com a essência ou identidade de algo. Seu critério de validade é o conceito enquanto criação exclusiva da filosofia.

Não é raro ouvirmos a expressão "estética" quando as pessoas se referem à beleza corporal. Principalmente no cotidiano dos profissionais de Educação Física, a palavra "estética" é repetida com certa freqüência. Esse termo foi empregado pela primeira vez por Alexander Baumgarten, no século XVIII, referindo-se à disciplina filosófica que tem como foco de estudo a essência do belo. Para Baumgarten, a estética é o estudo das sensações e percepções do belo, cujo valor é universal e sem compromisso de coincidir com a verdade, porque é, antes de tudo, livre manifestação da imaginação.

Moderno (2004) ressalta que a audácia da criação se manifesta na arte. Mas se a filosofia também é criação (de conceitos), ela toma emprestado algo da arte: a vocação de criar. Não criar obras de arte, mas criar conceitos que são obras filosóficas. A audácia da prática artística se dirige à filosofia, pois o conceito exige audácia de criação e autonomia do espírito. Assim o filósofo é antes de tudo artista quando cria conceitos. 
O termo "estética", em suas concepção inicial, não se referia necessariamente aos corpos, mas essencialmente às produções artísticas. Embora o termo tenha surgido no século XVIII, a estética enquanto campo de conhecimento inserido na filosofia se desenvolvia desde a Antiguidade. A preocupação com o Belo é intrínseca a atividade filosófica, junto a preocupação com a Verdade e com a Justiça.

O Belo para Xenofonte, discípulo de Sócrates, era considerado uma realidade ontológica. A beleza pertencia à esfera do Ser, do originário, do divino, efeito de uma potência transcendental. Em Xenofonte temos um significado ontológico do belo, isto é, o belo é uma idéia, é expressão do divino, é uma manifestação real e superior. É a presença da divindade. O belo nos inspira a filosofar, a buscar o conhecimento, a verdade, a essência (GRASSI, 1975; PANOFSKY, 1994).

Da mesma forma, Platão irá fazer um valioso relato sobre a beleza em seu famoso texto conhecido como "Banquete". Platão (2007) relata que Agatão teve premiada uma tragédia. Para festejar o prêmio, amigos são convidados à sua casa para um banquete (festa em que os homens gregos se reuniam para beber, comer, ouvir música, dançar e conversar). Fedro é o primeiro a discursar. Em seguida, Pausânias realiza seu discurso. O terceiro a discursar deveria ser Aristófanes, mas começou a soluçar sem parar. Ele pediu que Erixímaco o ajudasse como médico ou falasse no seu lugar até o soluço parar. Logo após, Aristófanes faz seu discurso e, por fim, Agatão. Sócrates ironiza seus amigos e diz que não procura a eloqüência das palavras ou a retórica sedutora, mas sim a verdade.

Sócrates conclui seu discurso deixando a mensagem de que na contemplação da beleza (que é a idéia do Bem) os humanos alcançam a ciência e o saber, por meio do qual concebem e dão nascimento às virtudes e por meio delas se tornam imortais. Amando a beleza interior, Eros nos faz desejar as almas belas. O amor se inicia pelos corpos belos, pela beleza física e há a partir daí uma ascese. Depois de se amar a beleza do corpo, ama-se a beleza da alma. No Banquete, Platão (2007) valoriza o corpo físico para o início da ascese.

No Fedro, Platão (2005b) também examina a beleza. Encontramos no Fedro alguns personagens: Sócrates, Fedro, Lísias, Isócrates. Logo no início, Fedro encontra-se fortemente entusiasmado com um discurso de Lísias (um sofista, mestre em retórica, talvez um dos responsáveis pela morte de Sócrates). Lísias era apaixonado por Fedro e fez um discurso sobre o amor destinado a ele. Sócrates irá mostrar a 
Fedro que o discurso de Lísias não é bom. Ele afirma não ter encontrado no discurso de Lísias o compromisso com a beleza e a verdade. Há excesso de retórica, mas pouca sabedoria em tal discurso, segundo Sócrates.

Braile (2006) ao fazer seu estudo sobre o Belo em Platão, afirma que o Fedro nos ajuda a compreender que o homem tende ontologicamente para o que é belo. $\mathrm{O}$ amor e a beleza são componentes fundamentais da ascese da alma ao mundo das idéias, da aparência à realidade, do sensível às idéias.

Nesse sentido, se quiséssemos pensar a existência de uma estética, enquanto estética corporal entre os gregos, teríamos dificuldades, pois o belo tinha um sentido ontológico tanto para Xenofonte quanto para Platão. Plotino, por sua vez, não segue um caminho muito diferentes dos autores anteriores. Para Plotino, o belo é o desejo da alma de retornar ao Uno (ao Idêntico) através das idéias contidas no intelecto. A alma sente atração pelo belo e repulsão pelo feio. Se a alma conhece o belo e não o feio, sentirá atração somente pelo belo. A feiúra é, pois, estranha a alma. O caminho para a virtude, para chegar ao belo, é se afastar da matéria. Na matéria não há beleza, visto que ela é o Não-Ser, o múltiplo, o diverso, o disforme. O sensível e as sensações não permitem que cheguemos ao belo. Não é a obra de arte que conduz a alma a ascese, mas sim as ações virtuosas realizadas através da deliberação racional.

Com isso, poderíamos "cair" na armadilha de concluir que os gregos preocupavam-se somente com a "beleza interior" e desprezavam a "beleza corporal". Nada seria mais ingênuo que tal conclusão. A beleza corporal era um aspecto muito importante na aquisição de virtude para o homem grego. Para compreender isto precisamos adentrar um pouco mais na história da Filosofia Antiga.

A aproximação entre Filosofia e Educação Física não é uma novidade do século XXI. Na civilização grega as atividades físicas foram reconhecidas como importantes. A própria história da Educação Física nasce com o surgimento da cultura e filosofia grega. A educação física era um elemento da paidéia: ginástica para o corpo e as artes das Musas (poesia, drama, oratória, etc.) para a alma. No Livro III da República de Platão (2005a), os diálogos de Sócrates e Glauco se concentram na educação pela música e pela ginástica. A ginástica não tinha objetivo de formação apenas do corpo, mas também do caráter. Buscava-se fortalecer o corpo e exercer o domínio sobre si próprio.

Na paidéia (educação do cidadão grego), o objetivo era a kalokagathia (educação moral e estética reunidas), isto é: educação do corpo/beleza e da moral/espiritual. O homem grego deveria se tornar o ISSN: 1983-930. 
"homem bom e belo". Homem "bom" é aquele que é completo e perfeito em si mesmo, permanecendo imutável e idêntico a si mesmo porque nada lhe falta que o faça mudar. Se nada lhe falta, não precisa transformar-se, pois já está aperfeiçoado. Já o homem "belo" é aquele que possui a perfeição da harmonia entre as partes de um todo e um todo que não possui nenhuma deformação ou desequilíbrio.

Se o homem grego é bom e belo, tornar-se-ia também justo e verdadeiro. Homem "justo" é aquele no qual há ordenação hierárquica e proporcional das partes componentes de um todo, sendo a superior (a razão) aquela que domina, comanda e dirige as inferiores. Por fim, homem "verdadeiro" é aquele que no qual há perfeita identidade e correspondência entre uma essência e uma existência, entre sua inteligibilidade e sua realidade, excluindo toda contradição.

Assim, o que nos motiva neste ensaio é compreender o conceito de "belo", a partir uma perspectiva filosófica. Em especial, destacaremos o filósofo alemão Kant, para pensar a beleza corporal na atualidade dos profissionais de Educação Física.

O objetivo deste ensaio é fazer uma breve discussão conceitual sobre as categorias "belo" e "sublime" em Kant, relacionando-os com a beleza corporal na contemporaneidade. Para isso, iniciaremos com uma discussão sobre o culto ao corpo e a difusão de padrões hegemônicos de beleza corporal. Em seguida, nos propomos a discutir se o conceito kantiano de "belo" se aplicaria ao que as pessoas chamam de homem "belo" e mulher "bela", assim como compreender se o conceito de "sublime" se aplica a juízos do tipo "Essa mulher é sublime" ou "Esse homem é sublime" quando as pessoas se referem à beleza corporal uns dos outros.

\section{BELEZA CORPORAL CONTEMPORÂNEA}

Peitoral, braços, coxas, pernas, barriga são partes do corpo, mas também algo mais, segundo Synnott (1993). Nós atribuímos idéias, imagens, significados, sentidos e valores aos sistemas biológicos. Nossos corpos e suas partes são carregadas com simbolismo público e privado, positivo e negativo, político e econômico, sexual e moral. O corpo não é somente um conjunto de pele e ossos ou uma máquina baseada em leis físico-químicas. Ele é também um locus de identidade, um emblema, uma escultura (FOURNIER, 2002, 2004) que utilizamos perante os outros. 
As pessoas pensam e se preocupam com o corpo mais do que com qualquer outra coisa. Apesar do hiperintelectualismo da cultura ocidental, a qual historicamente (de Platão, passando por Descartes, Kant até Hegel) privilegiou a mente e não o corpo, este está sempre presente e demandando atenção, cuidados, ajustes, retoques.

Nossos atributos de beleza ou feiúra, estatura ou peso, não somente afetam nosso círculo social, mas também afetam nossas formas de vida. A identidade do sujeito é claramente ilustrada pelas mudanças corporais. Pierre Bourdieu (1980a, 1980b, 1998a, 1998b), Luc Boltanski (1971, 2004), Marcel Mauss (1960), Michel Foucault $(1975,1976,1989$, 2001) nos mostram que as marcas corporais revelam muito mais do que o simples conjunto de músculos, ossos e alavancas.

Para Vigarello (2005) vivemos anos loucos. Os corpos atuais são liberados, magros, finos, musculosos, bronzeados, metamorfoseados. As mudanças na aparência feminina nas primeiras décadas do século XX são um exemplo canônico. Aspectos mas livres, linhas mais flexíveis, expressões mais sublinhadas, tudo colocado em cena. As pernas, os cabelos, a barriga esculpida se impõem. As marcas deixadas sobre o corpo pelas atividades externas (exercícios físicos, bronzeado) invadem as fotografias de moda. Nos anos 1930 já se ressalta a silhueta esbelta e esportiva, os membros finos e musculosos sem gordura localizada. "Meu peito é grande e caído, eu meço $170 \mathrm{~cm}$, eu não ousaria jamais colocar maiô, eu estou desesperada”, confessa uma mulher em 1937.

Parece que o corpo das mulheres se tornou alguma coisa que é preciso corrigir se ele não se encontra conforme essa vibração coletiva que é a moda, como aponta Noel (2005). As mulheres representavam $85 \%$ dos pacientes que realizavam cirurgias estéticas no Canadá em 2003. Ocorreu uma alta de $16 \%$ em relação a 2002, mais de 100.500 intervenções estéticas indo da injeção de Botox até a reconstrução do nariz e lipoaspiração.

Nos Estados Unidos, a cirurgia plástica estética passa de uma prática marginal, sem espaço para divulgação, antes da década de 1950, para uma especialidade reconhecida, regulamentada, e cada vez mais procurada pelos médicos. O belo se torna o normal e o feio o patológico. A beleza torna-se uma conquista pessoal, ocorrendo um crescimento de 600\% nas cirurgias para implante de silicone nos seios, $500 \%$ de lifting na região glútea e 420\% nas lipoaspirações. Foram realizados mais de 8,7 milhões de procedimentos estéticos, dentre os quais: quase três milhões de injeções da toxina botulínica, 320 mil 
lipoaspirações e 254 mil aumentos de mamas. De 1992 a 2003 ocorreu um grande crescimento no número de cirurgias plásticas com fins cosméticos (não terapêuticos), de 150 a $660 \%$ dependendo do procedimento. Outra tendência é o aumento dessas intervenções em faixas etárias cada vez mais precoces. Nos EUA, foram realizadas 3841 cirurgias para aumento de mamas em meninas menores de 18 anos em 2003 , um aumento de $24 \%$ em relação a 2002. No mesmo ano, houve um aumento de $950 \%$ em relação a 2002 no uso de botox. (POLINETO; CAPONI, 2007).

Com autonomia financeira, as mulheres se tornam cada vez mais as grandes consumidoras da indústria da moda, das cirurgias estéticas e dos produtos de beleza. A estética passa a ser "democratizada" na medida em que se pode comprar a beleza no mercado (GUÉRICOLAS, 1998).

No Brasil não é muito diferente: "Gosto de ficar durinha. Eu sei que o exagero é perigoso, que preciso de limites para não me machucar, mas me acho viciada mesmo. Se tenho tempo, malho até domingos e feriados", diz G.B., praticante de academia assídua. Nesse locus do fitness, ela realiza diariamente agachamentos com mais de cento e oitenta quilos, anda trinta metros com setenta quilos nas costas e empurra quase meia tonelada com as pernas nas máquinas. Com setenta e quatro quilos e seis por cento de gordura corporal, ela ainda se considera insatisfeita com seu físico (MOHERDAUI; VILLAVERDE, 2008).

$\mathrm{O}$ corpo tornou-se um referencial privilegiado para a construção das identidades pessoais. $\mathrm{O}$ que somos e o que devemos ser passou a ser definido a partir de nossos atributos físicos. A subjetividade se materializa, se fixa na carne, no músculo, na pele, na face, na aparência. Estar bem com o próprio corpo deixou de ser somente condição da vida política, religiosa ou sentimental. O encantamento pela aparência corporal nos leva a desejar uma forma física padronizada com a intensidade com que outrora desejávamos o crescimento espiritual, a honra na vida cívica e a felicidade sentimental. Uma extrema obsessão com a aparência física tornou-se evidente forçando o corpo a se exprimir de um modo novo. Do fisiculturismo a anorexia, percebe-se que algo no imaginário cultural traz o corpo para o centro da formação da identidade. O corpo começou a tomar o lugar de outras instâncias na constituição da identidade (COSTA, 2005, 2009).

"Minha mãe não acredita que eu deixo de jantar domingo à noite para ir à academia. Mas domingo é o melhor dia da semana, estou descansado e cheio de energia. Para mim, treinar é sagrado. [...] Meu pé 
estava ruim, mas o resto do corpo estava funcionando. Não tinha porque ficar parado" revela E.B, que praticava musculação de madrugada na academia, para evitar ser impedido pelos professores durante o dia, em razão de seu pé engessado (MOHERDAUI; VILLAVERDE, 2008).

Já M.L gasta por mês com tratamentos de beleza cerca de R $\$ 12.000,00$. Ela testou massagens estéticas, drenagem linfática, botox e todas as formas que encontrou para combater a flacidez do corpo. Igualmente, a funcionária pública P.F. gastou cerca de R \$ 8000,00 em uma sessão de Thermacool, aparelho que promete acabar com a celulite e endurecer os músculos da região glútea (MEDINA, 2008).

A preocupação estética se torna um meio de transformar a existência. Mudar a aparência ganha o status de mudar de identidade. Não sabemos exatamente as causas para essas transformações estarem atingido mais o público feminino, mas não se pode negligenciar que distúrbios relacionados a imagem corporal, como anorexia e bulimia predominam nas mulheres. Dos casos de transtorno de imagem corporal, $98 \%$ das pessoas atingidas são mulheres (APA, 1994; ATTIE; BROOKS-GUNN, 1989; CARPENTER et al., 2000; CORDAS; CLAUDINO, 2002; FISCHER et al., 1995; FOWLER, 1989; GIORDANI, 2006; KOSTANKI; GULLONE, 1998).

O culto ao corpo deixa de ser um processo de melhora externa para se tornar um processo de identificação a serviço de um sujeito que não se aceita pelo que é, mas que quer ser conhecido pelo que deseja parecer. O culto ao corpo não é mais somente uma reconstrução narcísica, mas se torna um modo de subjetivação pelo qual o sujeito se coloca em uma cultura construindo sua materialidade corporal identitária. O meu rosto, a qualidade dos meus cabelos, a cor dos meus olhos, o tamanho dos meus músculos, a maciez da minha pele e a quantidade de gordura no meu corpo revelam o meu caráter e as minhas qualidades. Isto é, minha aparência física revela minha identidade supostamente "real". Descartes foi ultrapassado. Sua expressão "Eu não sou o meu corpo" foi enterrada. O cogito está sendo substituído pela aparência corporal.

\footnotetext{
A fase da vida em que eu mais gostei do meu corpo foi aos 18 anos. Toda semana eu anotava minhas medidas, da panturrilha ao antebraço, para ver se eu tinha aumentado de tamanho. Se não crescia, não saía de casa. Achava um absurdo minhas amigas me chamarem para sair com aquela perna tão fina, revela N.A, praticante regular de academia (MOHERDAUI; VILLAVERDE, 2008).
}

Há uma racionalização instrumental ascética do cotidiano (através de dietas e exercícios rigorosos) realizada em nome da saúde, pois o discurso da busca pela boa saúde cresce a cada dia. Entretanto, como Conexões: revista da Faculdade de Educação Física da UNICAMP, Campinas, v. 8, n. 2, p. 47-67, maio/ago. 2010. ISSN: 1983-930. 
Sabino e Luz (2007b) afirmam, a maioria dos indivíduos, que diz se preocupar com a saúde, busca a construção da forma corporal ideal entendida como grande volume muscular e menor quantidade de gordura possível. Diante disso, as atividades físicas atuais, estão ligadas à forma física condizente com as rigorosas normas de beleza.

\begin{abstract}
Não vou lá para fazer fisioterapia. Faço a supersérie, que só termina com a fadiga total do músculo. Não me considero viciada, mas não vivo sem minha musculação. [...] Em pouco tempo comecei a ver resultado: meu braço tomando forma, meu abdômen formando gominho, meu ombro ficando fibrado relata R.L, que pratica musculação seis vezes por semana (MOHERDAUI; VILLAVERDE, 2008).
\end{abstract}

Para Ortega (2003), as práticas de ascese via corpo enfatizam os procedimentos estéticos na construção das identidades pessoais. Trata-se da formação de um sujeito que atribui ao corpo o lugar da moral. A subjetividade se somatiza e a aparência corporal torna-se elemento central na auto-identidade. Portanto, as práticas bioascéticas garantem ao corpo maximizar o prazer, desafiar os limites orgânicos e superinvestir na pele, no músculo, na face, nos cabelos, enfim, em cada parte do corpo.

A "cultura do músculo" encontra-se, agora, em toda os domínios da vida social. A reivindicação muscular democratizou-se, as práticas do body-building tendem a se generalizar e a potência anatômica se exibe como um espetáculo permanente. Não há apenas um corpo que pretende se esconder do olhar censurador ou depreciativo do outro, mas há também um novo tipo ideal de corpo que pretende tirar benefícios no campo do olhar, saturá-lo de massa muscular. O músculo, assim, torna-se uma marca social valorizada. Ele é um dos modos privilegiados de visibilidade do corpo no anonimato das fisionomias. Do bíceps dos homens ao quadríceps e glúteo máximo das mulheres, todos almejam visibilidade (COURTINE, 1995).

O músculo representa o bem simbólico mais valioso e almejado no campo do fitness, enquanto a gordura representa a sujeira, a desordem. A busca da "forma perfeita" torna-se um meio de adquirir distinções e honras sociais (MATTOS, 2008).

Beausolei (1998) em seu estudo com inúmeras mulheres percebeu que a maior parte se acha muito gorda, seja em relação ao seu peso ou às suas proporções corporais. Nesse contexto social, muitas mulheres possuem uma relação de dor e sofrimento com seu corpo. A magreza ou gordura é uma preocupação de quase todas e tema constante de debate. Diante da obrigação da magreza, a relação das mulheres com a 
alimentação é particularmente atormentada. A fim de evitar problemas de peso e do corpo que "amolece", as mulheres ressaltam que é importante envelhecer mantendo a forma.

Saúde e boa forma se inscrevem sobre o corpo podendo ser "lidas" pelos outros. Qualquer um pode "ler" e "enxergar" a saúde de alguém através da boa forma corporal. Uma das mulheres entrevistada encara o envelhecimento como a aproximação com a imagem do corpo de sua mãe e avó. Ela faz referência a alguns sinais do envelhecimento: o corpo murcho, os seios caídos e as bundas moles.

O EU ostenta-se na superfície do corpo e a identidade passa a ser modelada como uma produção corporal dominável. A saúde torna-se, assim, cada vez mais submetida à estética, o que significa que estar fora dos padrões de beleza do grupo e de suas práticas é estar sem saúde e excluído de sua convivência, principalmente porque a construção identitária dos indivíduos está, agora, relacionada à construção e manutenção de sua forma física (LE BRETON, 2003).

Diante disso, iremos discutir se o conceito kantiano de "belo" se aplicaria ao que as pessoas chamam de homem "belo" e mulher "bela" na atualidade e, por conseguinte, compreender se o conceito de "sublime" se aplica a juízos do tipo "Essa mulher é sublime" ou "Esse homem é sublime" quando as pessoas se referem à beleza corporal uns dos outros.

\section{O CONCEITO KANTIANO DE "BELO" SE APLICARIA AOS CORPOS ATUAIS?}

Kant (1724-1804) é o famoso filósofo da Crítica da Razão Pura (1983) que sustentou o argumento de que nossa relação com a realidade não é direta (não conhecemos as coisas-em-si, mas somente os fenômenos). Não podemos compreender certos aspectos do real, mas somente pensá-los. Nossa apreensão do mundo passa necessariamente pelas formas a priori da sensibilidade e do entendimento que permitem nossos juízos. Assim, Dortier (2002) ressalta que Kant limitou nossas experiências aos nossos próprios esquemas mentais: tempo, espaço, substância e causalidade.

Se a Crítica da Razão Pura concluiu que o conhecimento humano é incapaz de transcender o mundo sensível; a Crítica da Razão Prática concluiu que a conduta humana não teria sentido sem a suposição de um mundo inteligível. A intencionalidade da ação e a obediência ao dever vão permear essa obra de Kant, na qual estará sempre em foco a unidade formal da razão humana. A Crítica da Faculdade do Juízo, por ISSN: $1983-930$. 
sua vez, assegura a transição entre o entendimento e a razão, estabelecendo um intermediário entre o mundo sensível e mundo inteligível. Os juízos de conhecimento, moral e estético são fundamentados por Kant a partir do sujeito transcendental estruturado pelo entendimento, razão e faculdade do juízo. A filosofia transcendental kantiana é aquela que estabelece os elementos a priori do sujeito que nos permitem elaborar os juízos.

Cada Crítica de Kant nos coloca uma questão central:

Crítica da Razão Pura $\rightarrow$ Como são possíveis os juízos de conhecimento?

Crítica da Razão Prática $\rightarrow$ Como são possíveis os juízos morais?

Crítica da Faculdade do Juízo $\rightarrow$ Como são possíveis os juízos?

A Crítica da Faculdade do Juízo nos mostra que, entre o entendimento (organizador de nossos conhecimentos), e a razão (princípio de nossas ações), existe uma faculdade mediadora (a faculdade de julgar) cuja função é pensar o mundo sensível em referência ao mundo inteligível. É essa faculdade de julgar que será aplicada ao belo e ao sublime. Na Crítica da Faculdade do Juízo, Kant acaba por produzir uma teoria estética ao fazer analíticas e dialéticas da faculdade do juízo estético (COOPER, 2007; CRAWFORD, 1974; KEMAL, 1986; KEMAL, 1992; MCCLOSKEY, 1987).

Na Crítica da Razão Pura, Kant tratava somente dos juízos determinantes (de determinar os casos particulares em relação a uma regra geral). Tais juízos de realizam segundo leis prescritas a priori (independentes da experiência, necessárias, universais) pelo entendimento. Mas há na natureza um grande número de leis que não são determinadas diretamente pelas leis a priori do entendimento. Logo, seremos obrigados a pensar do particular ao universal. Esse é o papel do juízo reflexionante (da diversidade do particular das leis para um princípio unificador transcendental). Somos conduzidos à idéia de finalidade. A idéia de finalidade é um conceito a priori e regulador. O juízo de finalidade serve de intermediário entre a causalidade natural e a finalidade moral. E por que a necessidade desse intermediário?

Porque a divisão elaborada por Kant entre "Filosofia Teórica" (domínio da natureza/concernente ao conhecimento/dependente do entendimento) e a "Filosofia Moral" (domínio da liberdade/concernente à ação/dependente da razão) gerou uma distância entre o mundo da natureza e o mundo da liberdade? Como estabelecer um nexo entre o sensível (objeto de conhecimento) e o inteligível (objeto do pensamento)? Diante dessa dúvida ele elabora a Crítica do Juízo. Se as leis naturais obedecem ao Conexões: revista da Faculdade de Educação Física da UNICAMP, Campinas, v. 8, n. 2, p. 47-67, maio/ago. 2010. ISSN: 1983-930. 
princípio da causalidade e as leis morais o princípio da finalidade, como é possível um acordo entre causalidade e finalidade? Como passar da ordem da liberdade para a ordem da natureza? Cabe a Crítica da Faculdade do Juízo definir as condições da possibilidade do juízo de finalidade (PASCAL, 2008).

Para Santos (2006), a dificuldade maior da Crítica da Faculdade do Juízo é o fato de o Kant remeter para a mesma faculdade do espírito (a faculdade de julgar) e para o mesmo princípio transcendente de apreciação (a conformidade a fins) o fenômeno da arte humana e os fenômenos da natureza estética e teleológica. Kant organiza os princípios da sua filosofia em três faculdades do espírito (o entendimento, a razão, o juízo reflexionante) cabendo ao juízo reflexionante a apreciação estética. O que se passa em nós quando apreciamos esteticamente um objeto? O que esse objeto provoca em nossas faculdades? São essas questões que Kant tenta responder na Crítica da Faculdade do Juízo.

Ao escrever a Analítica do Belo, Kant (1995) chega a algumas conclusões que pretendemos discutir neste trabalho:

a) Gosto é a faculdade de ajuizamento de um objeto ou de um modo de representação mediante uma complacência (prazer) ou descomplacência independente de todo interesse. O objeto de uma tal complacência chama-se belo;

b) Belo é o que apraz universalmente sem conceito;

c) Beleza é a forma da conformidade a fins de um objeto, na medida em que ela é percebida nele sem representação de um fim;

d) Belo é o que é conhecido sem conceito como objeto de uma complacência necessária.

A analítica do belo possui quatro categorias que serão aplicadas ao juízo estético: qualidade, quantidade, relação a fins, modo. O primeiro momento do juízo estético diz respeito à qualidade. Do ponto de vista da qualidade, o gosto é a faculdade de julgar um objeto ou um modo de representação mediante um agrado ou um desagrado, sem qualquer interesse. O objeto de um tal agrado chama-se belo. O agrado (prazer) de ordem subjetivo produzido pelo belo independe de todo interesse sensível ou racional ligado ao objeto ou à sua representação. Logo, os juízos do senso comum: "Esta mulher é bela" ou "Este homem é belo" não podem ser considerados como juízos estéticos, segundo Kant, no que diz respeito à qualidade, pois, na maioria dos casos há um interesse no objeto que está para além da contemplação. Se o juízo estético não for contemplativo e desinteressado, o que raramente é nas relações cotidianas entre homens e mulheres, não pode ser considerado um juízo estético na perspectiva kantiana.

Conexões: revista da Faculdade de Educação Física da UNICAMP, Campinas, v. 8, n. 2, p. 47-67, maio/ago. 2010. ISSN: 1983-930. 
O segundo momento do juízo estético diz respeito à quantidade. Kant irá afirmar que belo é o que apraz universalmente sem conceito. $\mathrm{O}$ que é belo não necessita de conceito, pois apraz por si mesmo. A universalidade estética que é conferida a um juízo não conecta o predicado da beleza ao conceito do objeto. Não há precisamente algo no objeto para que o possamos qualificá-lo de belo. Não precisamos conhecer o conceito, nem a utilidade de algo para encontrar nele beleza. O conceito para Kant (1983, 2003) é uma representação universal por notas comuns. Isto é, o conceito é uma representação universal ou uma representação daquilo que é comum a diversos objetos, na medida em que esta representação pode estar contida em diferentes objetos. Ser universal não é se aplicar a vários objetos, mas poder se aplicar a vários objetos. Por exemplo: cachorro é um conceito. É uma representação universal, mesmo que só exista 1 cachorro no mundo. Outro exemplo: homem é um conceito. É uma representação universal que possui notas comuns que podem ser compartilhadas por diferentes objetos. Falar de um "conceito universal" é uma tautologia, porque todo conceito já é universal.

Enquanto o juízo pode ser universal ou particular, o conceito é sempre universal. Entretanto, quando nos referimos ao uso do conceito, aí sim podemos dizer que ele pode ser particular, pois seu uso se dá no juízo. A forma de um conceito é sempre fabricada pelo entendimento. Os conceitos organizam/regularizam/normatizam as representações singulares disponíveis sensivelmente. Logo, o conceito atribui uma rega de organização dos dados sensíveis. Enquanto há doze formas de juízos, segundo Kant, só há uma forma de conceito: a universalidade. Embora a matéria (conteúdo) do conceito possa variar infinitamente, há apenas uma forma.

O juízo estético, diferentemente do juízo de conhecimento e do juízo moral, não é fundado em conceitos. O juízo estético reivindica a universalidade de um juízo que não se funda em conceitos objetivos, mas em um sentimento de prazer. O belo na Crítica da Faculdade do Juízo não se fundamenta em um conceito do entendimento. Nesse sentido, a universalidade subjetiva é a universalidade de um juízo que tem como fundamento de determinação não um conceito, mas o poder de julgar enquanto tal. Sendo esse juízo justamente o juízo de gosto sobre o belo.

A hipótese de Rego (2005) é de que ao juízo de gosto sobre o belo, em virtude de seu fundamento de determinação e do registro de universalidade subjetiva que ele delimita, pertence um privilégio fundacional em relação aos juízos de conhecimento. Como o juízo estético não é interessado, ele é, portanto, universal, pois caso fosse interessado no objeto não poderia ser necessário e universal. 
O belo não é contingencial, particular e arbitrário na filosofia kantiana. Isto é, não há belo para mim ou para você. Não posso dizer que a mulher A ou a mulher B são belas. Não posso entrar em uma academia de ginástica e dizer: “Aquela mulher é bela”. Há apenas o agradável para mim e o agradável para você, mas o belo é universal e se aplica a mim e a você. O objeto belo provoca em nós um prazer universal. Logo, dizer que a mulher $\mathrm{X}$ é bela ou o homem Y é belo, nos referindo a beleza corporal, não pode ser um juízo estético segundo Kant. Posso apenas dizer que a mulher X me é agradável e que o homem Y não me é agradável.

Kant (1995) afirma que seria ridículo se alguém se gabasse de seu gosto identificando-o com o belo. Um edifício, uma roupa, um conceito filosófico, um poema, uma música, uma mulher, um homem não podem ser belos ou belas para uma pessoa. Se algo apraz somente a um sujeito, não pode ser chamado de belo, somente de agradável ou desagradável. Para tomar algo por belo, é preciso que todos tenham a mesma complacência diante do objeto. O belo, para Kant, não é algo que carece de discussão, debate e contingências, mas somente o agradável é contingencial. Vale ressaltar, que o agradável possui regras gerais (podendo, por isso, ser unânime entre muitas pessoas), mas não regras universais.

O terceiro momento do juízo estético diz respeito à conformidade a fins. Kant quer argumentar que o juízo estético não tem finalidade, é "como se" tivesse uma finalidade. Se houver interesse e finalidade não pode ser um juízo estético. A conformidade a fins é, portanto, um princípio do sujeito transcendental e não do objeto. É o ser humano como sujeito universal dotado de suas faculdades que enxerga nexos e finalidades na natureza.

O quarto momento do juízo estético diz respeito à modalidade. Esta categoria diz respeito à "necessidade" e à "contingência". Necessário é tudo aquilo que é independente da experiência, que só pode ser de uma única forma (pois seu contrário implica em contradição) e é universal (igual em todos os seres humanos), enquanto contingente é tudo que depende da experiência, pode se apresentar de diversas formas e varia conforme as pessoas. Enquanto o juízo sobre o agradável é contingente: A mulher A me é agradável ou a mulher B não me é agradável, o juízo estético é universal, pois implica em um prazer universal transcendental. A idéia de necessidade não se fundamenta na experiência, ela é uma idéia $a$ priori, pertence unicamente ao sujeito racional. 
Mas uma vez ratificamos que o que chamamos de beleza corporal na contemporaneidade quando olhamos uma pessoa na rua, no trabalho, na escola, na universidade, na academia de ginástica, não pode ser considerada um juízo estético na filosofia kantiana. Pois para Kant (1995), o juízo de gosto é universal (ocorre da mesma maneira em todas as pessoas), o que é muito diferente da experiência cotidiana contingencial que temos com o agradável. Independente de toda inclinação e de todo conceito, a satisfação provocada pelo belo deve ser sentida igualmente em todos nós.

A partir da leitura da Analítica do Belo de Kant (1995) podemos afirmar que o juízo estético é:
a) contemplativo;
b) desinteressado do objeto;
c) universal;
d) não é fundado sobre conceitos;
e) não tem finalidade.

Logo, quando nos referimos à beleza corporal das pessoas ao nosso redor, conhecidas ou desconhecidas, não estamos emitindo juízos estéticos segundo a teoria filosófica kantiana. No máximo estaríamos nos referindo ao que é agradável, mas não ao que é belo. Dizer "A é belo" é dizer algo do meu próprio sentimento e não do objeto de desejo. O interesse no juízo estético está no sentimento do sujeito e não no objeto.

\section{O conceito kantiano de "Sublime" se aplicaria aos corpos atuais?}

O segundo livro da primeira parte da Crítica da Faculdade do Juízo é a Analítica do Sublime. A definição de sublime para Kant (1995) é o que é absolutamente grande ou tudo aquilo em comparação com o qual tudo é menor.

Para Pascal (2008), o belo e o sublime têm em comum a característica de agradarem por si mesmos, de maneira desinteressada, universal e necessária. Enquanto o belo se refere a um objeto limitado, finito, despertando em nós um sentimento de vida intensificada, o sublime se refere a um objeto ilimitado, despertando em nós um sentimento das forças vitais e uma expansão potencial dessas forças. Na beleza há harmonia entre a representação e o juízo. O sublime destrói essa harmonia. O medonho, a feiúra, o horrível podem despertar em nós o sentimento do sublime. Logo, a expressão do senso comum "Essa mulher é sublime" ou "Essa mulher tem uma beleza sublime" quando se referem à beleza corporal não 
podem ser inseridas conceitualmente numa perspectiva kantiana, pois o sublime pode ser algo extremamente grande e horrível.

Além disso, o objeto sensível não é sublime, ele apenas desperta em nós o sentimento do sublime. Nenhuma pessoa, objeto ou fenômeno da natureza é sublime, mas é o uso que nosso espírito faz do objeto que nos induz a projetar nesse objeto o sentimento do sublime. O sublime não se encontra nos objetos, mas em nosso espírito. Ele não está contido em nenhum objeto sensível. Assim, Kant (1995) afirma "o sublime não deve ser procurado nas coisas da natureza, mas unicamente em nossas idéias” (p. 96). O objeto não pode ser considerado sublime, mas a disposição de nosso espírito, nosso ânimo, nossa alma.

O sublime é tudo aquilo que é absolutamente grande, isto é, para além de toda comparação com qualquer medida objetiva, que nos leva a tentar compreender esse algo maior do que nós. É uma mistura de medo com contentamento. Diante do sublime nos consideramos pequenos diante da natureza, mas muito maiores diante do poder da nossa razão e imaginação de contemplá-lo. Ao olhar um vulcão em erupção ou um tornado se aproximando, só o ser humano é capaz de parar e admirar a natureza em sua máxima expressão. Dizer que uma pessoa é sublime, não tem relação alguma com a analítica do sublime de Kant.

Do ponto de vista do juízo estético, o pequeno e o grande não são noções matemáticas, mas sim noções subjetivas ligadas a sentimentos de respeito ou desprezo. O sentimento do sublime nos abre para o que está além do sensível. Na presença do belo, sentimos um prazer. Na presença do sublime, sentimos um sentimento de prazer e desprazer, vindo da falta de conformidade da imaginação, da avaliação estética da grandeza e da avaliação da razão. A percepção de uma desproporção entre os dados da sensibilidade e as possibilidades da razão provoca, após uma repulsa inicial, um sentimento de atração e de harmonia com as leis da razão, que aspira dominar e ultrapassar a sensibilidade.

A experiência do belo natural é muito mais fecunda do que a experiência do sublime da natureza, pois no sublime a natureza revela-se com um poder de inesgotável produção finalizada de belas formas e de incontáveis seres vivos, mas também como um caótico e incomensurável poder de destruição. Se perante o belo somos estimulados a admirar e amar, perante o sublime agimos com admiração, respeito, mas medo e temor. A sublimidade que experimentamos perante certos fenômenos é uma sublimidade do próprio espírito, ao qual, precisamente na violência que a natureza lhe impõe, é dado experimentar sob 
forma sensível a sua condição supra-sensível. Enquanto o belo prepara-nos para amar de um modo desinteressado, o sublime nos comove para estimar em toda sua magnitude (SANTOS, 2006).

\section{CONCLUSÃO}

O objetivo deste ensaio foi discutir, a partir da Crítica da Faculdade do Juízo, a coerência e validade de afirmações cotidianas como "João é um homem belo" ou "Maria é uma mulher bela" no que diz respeito à beleza corporal (cultural, social e histórica).

Estendemos nossa discussão para algumas afirmações do tipo "João é um homem sublime" ou "João tem uma beleza sublime". Esses termos "belo" e "sublime", tais quais empregados nessas frases anteriores podem ser compreendidos como Kant os emprega na Crítica da Faculdade do Juízo? Não. A Analítica do Belo e a Analítica do Sublime são construções teórico-conceituais filosóficas de Kant muito diferentes dessas afirmações existentes no senso comum.

Percebemos que o belo em Kant é contemplativo, universal, desinteressado, não fundado sobre conceitos e sem finalidade, enquanto o sublime é o sentimento que temos diante de algo extremamente grande que causa admiração e temor. $\mathrm{O}$ sublime comove enquanto o belo atrai. Tanto o belo quando o sublime pertencem ao sujeito transcendental universal e não aos objetos sensíveis. Se quisermos pensar a partir da estética kantiana devemos dizer "Maria é uma mulher agradável para mim" e não "Maria é uma mulher bela para mim". Da mesma forma, o sublime se aplica às forças da natureza e a infinitude da natureza. Não devemos, portanto, dizer "João é um homem sublime". Isso não tira a legitimidade do senso comum de fazer tais usos dos termos belo e sublime, mas foge ao uso dado filosoficamente por Kant.

\section{REFERÊNCIAS}

AMERICAN Psychiatric Association (APA). Diagnostic and statistical manual of mental disorders. $4^{\text {th }}$ ed. Washington: American Psychiatric Association, 1994.

ATTIE, I.; BROOKS-GUNN, J. Development of eating problems in adolescent girls: a longitudinal study. Dev Psychol, v. 25, p. 70-79, 1989.

BEAUSOLEI, N. Corps, santé, apparence et vieillissement dans les énoncés de femmes francophones em Ontario. Reflets, v. 4, n. 1, p. 53-74, 1998. 
BOLTANSKI, L. Les usages sociaux du corps. Ann E.S.C, n. 26, v. 1, p. 205-233, 1971.

. As classes sociais e o corpo. 4. ed. São Paulo: Paz e Terra, 2004.

BOURDIEU, P. Le capital social. Actes Rech Sci Soc, n. 31, 1980a.

. Questions de sociologie. Paris : Les Éditions de Minuit, 1980b.

. Méditations pascaliennes. Paris : Editions du Seuil, 1998a.

. La domination masculine. Paris : Editions du Seuil, 1998b.

BRAILE, L. J. Os sentidos do belo no banquete de platão. 2006. Dissertação (Mestrado em Letras) Universidade Federal Fluminense, Niterói, 2006.

CARPENTER, K. M. et al. Relationships between obesity and DSM-IV major depressive disorder, suicide ideation, and suicide attempts: results from a general population study. Am J Publ Health, v. 90, p. 251-257, 2000.

COOPER, D. E. Immanuel Kant. In: MURRAY, C. (Ed.). Key writers on art: from antiquity to the nineteenth century. New York: Routledge, 2007.

CORDAS, T. A.; CLAUDINO, A. M. Transtornos alimentares: fundamentos históricos. Rev Bras Psiq, São Paulo, v. 24, p. 3-6, 2002.

COSTA, J. F. O vestígio e a aura: corpo e consumismo na moral do espetáculo. 4. ed. Rio de Janeiro: Garamond, 2005.

COSTA, J. F. O corpo é o maestro. Rev Hist Bibl Nac, Rio de Janeiro, n. 40, ano 4, p. 38-43, jan. 2009.

COURTINE, J.-J. Os Stakhanovistas do narcisismo: body-building e puritanismo ostentarório na cultura americana do corpo. In: SANT’ANNA, D. B. (Org.). Políticas do corpo: elementos para uma história das práticas corporais. São Paulo: Estação Liberdade, 1995.

CRAWFORD, D. Kant's aesthetic theory. Madison: Wisconsin University, 1974.

DELEUZE, G.; GUATTARI, F. Qu'est-ce que la philosophie ? Paris: Minuit, 1991.

DORTIER, J-F. Emmanuel Kant. Sci Hum, n. 38, sep./nov. 2002.

FISCHER, M. et al. Eating disorders in adolescents: a background paper. J of Adolesc Health Care, New York, v. 16, n. 6, p. 420-437, 1995.

FOUCAULT, M. Surveiller et punir. Paris: Galllimard, 1975. . Histoire de la sexualité I: la volonté de savoir. Paris: Gallimard, 1976. . Résumé des cours (1970-1982). Paris: Julliard, 1989. . L’herméneutique du hujet. Paris: Gallimard-Seuil, 2001.

FOURNIER, M. Le corps, emblème de soi. Sci Hum, n. 132, nov. 2002. 
FOURNIER, M. Souci du corps et sculpture de soi. Sci Hum, n. 154, nov. 2004.

FOWLER, B. A. The relationmship of body image perception and weight status to recent change in weight status of adolescent female. Adolesc, v. 24, n. 95, p. 557-568, 1989.

GIORDANI, R. B. F. A Auto-imagem corporal na anorexia nervosa: uma abordagem sociológica. Psicol \& Soc, v. 18, n. 2, p. 81-88, maio/ago. 2006.

GUÉRICOLAS, P. Le nouveau culte des apparences: sois belle et battante. Gaz Fem, v. 20, n. 1, p. 1932, maio/jun. 1998.

GRASSI, E. Arte como antiarte: a teoria do belo no mundo antigo. São Paulo: Duas Cidades, 1975. KANT, I. Crítica da razão pura. São Paulo: Abril Cultural, 1983. (Coleção Os Pensadores). Crítica da faculdade do juízo. 2 ed. Rio de Janeiro: Forense Universitária, 1995. . Lógica. 3 ed. Rio de Janeiro: Tempo Brasileiro, 2003.

KEMAL, S. Kant and fine art. Oxford: Clarendon Press, 1986. Kant's aesthetic theory. London: St Martin's Press, 1992.

KOSTANKI, N.; GULLONE, E. Adolescent body image dissatisfaction: relation with self-esteem, anxiety, and depression controlling body mass. J Child Psychol Psych, v. 39, n. 2, p. 255-262, 1998.

LE BRETON, D. Adeus ao corpo: antropologia e sociedade. Campinas: Papirus, 2003.

MAIGNÉ, C. Qu'est-ce que la philosophie ? Sci Hum, n. 3, mars/juin. 2005.

MATTOS, R. S. Nasci de novo: sobrevivendo ao estigma da gordura: um estudo de caso sobre obesidade. 2008. Dissertação (Mestrado em Saúde Coletiva) - Instituto de Medicina Social, Universidade do Estado do Rio de Janeiro, Rio de Janeiro, 2008.

MAUSS, M. Sociologie et anthropologie. Paris: PUF, 1960.

MCCLOSKEY, M. Kant's aesthetic. London: Macmillan, 1987.

MEDINA, A. Beleza Comparada: dez mulheres contam as loucuras - e os gastos - que fazem para manter-se sempre jovens e bonitas. Veja Rio, Rio de Janeiro, n. 8, p. 19-24, 27 fev. 2008.

MODERNO, J. R. L'esthétique de la philosophie chez Deleze: remarques adorniennes sur la théorie deleuzienne de la création du concept philosophique. Revue d'Esthétique, Paris, v. 45, p. 109-119, 2004. MOHERDAUÍ, B.; VILLAVERDE, S. Quanto mais exercício melhor? Não quando se passa dos limites. Quem malha pesado todos os dias e não sabe viver sem isso pode estar fazendo mal à própria saúde. Veja, Rio de Janeiro, n. 5, p. 56-63, 6 fev. 2008.

NOEL, L.M. Être parfaite, partout partout. Gaz Fem, v. 26, n. 5, p. 8, mar./abri. 2005. 
ORTEGA, F. Práticas de Ascese Corporal e Constituição de Bioidentidades. Cad Saúde Colet, Rio de Janeiro, v. 11, n. 1, p. 59-77, 2003.

PANOFSKY, E. Idea: contribuição à história do conceito da antiga teoria da arte. São Paulo: Martins Fontes, 1994.

PASCAL, G. Compreender Kant. 4. ed. Petrópolis: Vozes, 2008.

PLATÃO. A República. São Paulo: Martin Claret, 2005a.

. Fedro. São Paulo: Martin Claret, 2005b.

. Banquete. São Paulo: Martin Claret, 2007.

POLI NETO, P.; CAPONI, S. N. C. A medicalização da beleza. Interface: comunicação, saúde e educação, Botucatu, v. 11, n. 23, p. 569-584, set./dez. 2007.

REGO, P. C. Reflexão e fundamento: sobre a relação entre gosto e conhecimento na estética de Kant. Kriterion, Belo Horizonte, n. 112, p. 214-228, dez. 2005.

SABINO, C. O uso ritual de esteróides anabolizantes em academias de musculação: uma abordagem antropológica. Arq Mov: revista eletrônica da Escola de Educação Física e Desportos - UFRJ, Rio de Janeiro, v. 1, n. 1, p. 7-16, jan./jun. 2005.

. A louridade da loura. In: GOLDENBERG, M. (Org.). O corpo como capital: estudos sobre gênero, sexualidade e moda na cultura brasileira. Barueri: Estação das Letras e Cores, 2007a.

SABINO, C.; LUZ, M.T. Ritos da forma: a construção da identidade fisiculturista em academias de musculação na cidade do Rio de Janeiro. Arq Mov: revista eletrônica da Escola de Educação Física e Desportos - UFRJ, Rio de Janeiro, v. 3, n. 1, p. 51-68, jan./jun. 2007 b.

SANTOS, L. R. Da experiência estético-teleológica da natureza à consciência ecológica: uma leitura da crítica do juízo de Kant. Trans/Form/Ação, São Paulo, v. 29, n. 1, p. 7-29, 2006.

SYNNOTT, A. The body social: simbolism, self and society. London: Routledge, 1993.

VIGARELLO, G. Années folles: le corps métamorphosé. Sci Hum, n. 4, nov./dez. 2005. 
RAFAEL MATTOS

Instituto de Educação Física e Desportos da Universidade do Estado do Rio de Janeiro

\section{Referencia do artigo}

ABNT

MATTOS, R. S. Uma analítica da beleza corporal: notas a partir de Kant. Conexões, v. 8, n. 2, p. 47-67, 2010.

APA

Mattos, R. S. (2010). Uma analítica da beleza corporal: notas a partir de Kant. Conexões, 8(2), 47-67.

\section{VANCOUVER}

Mattos, RS. Uma analítica da beleza corporal: notas a partir de Kant. Conexões, 2010; 8(2): 47-67.

\section{Recebido em: 03/2010}

Aceito para publicação em: jun./2010 